\title{
Formação Docente e EducaÇão a Distância: UM ESTUdo do Cenário educativo de Santa Catarina
}

\author{
Teacher Training and Distance Education: a study of educational \\ scenario of Santa Catarina
}

\author{
Rafael Pereira Ocampo Moré \\ Mestre do Programa de Pós-Graduação em Administração, Universidade Federal de Santa Catarina - Florianópolis - SC, Brasil. \\ E-mail: rafamore@gmail.com
}

\section{Grace Tavares Vieira}

Mestranda do Programa de Pós-Graduação em Educação em Ciências: Química da Vida e Saúde, Universidade Federal do Rio Grande - Rio Grande - RS, Brasil.E-mail: grace.vieira@capes.org.br

\section{Márcia Santiago de Araújo}

Professora do Programa de Pós-Graduação em Educação em Ciências: Química da Vida e Saúde, Universidade Federal do Rio Grande - Rio Grande -RS, Brasil.E-mail: grace.vieira@capes.org.br

\section{Alexandre Marino Costa}

Professor do Programa de Pós-Graduação em Administração, Universidade Federal de Santa Catarina - Florianópolis - SC, Brasil.

E-mail:marino@cse.ufsc.br

\section{Resumo}

A formação docente é fator preponderante na luta pela qualidade na educação do Brasil. A partir da promulgação da Lei de Diretrizes e Bases (LDB), em 1996, tem-se o desafio de formar novos professores e, para isso, verifica-se na Educação a Distância $(\mathrm{EaD})$ uma excelente alternativa de acesso à educação superior pública. A EaD é definida como proposta educativa que utiliza tecnologias para diminuir a distância entre as Instituições de Ensino Superior (IES) e os alunos, e é nesse contexto que surge a Universidade Aberta do Brasil (UAB), que atualmente é a principal política de formação docente por meio da EaD. O objetivo do trabalho é apresentar as políticas de formação docente inseridas no estado de Santa Catarina, sendo detalhada a UAB no cenário brasileiro e catarinense e analisada a inserção de TICs nas escolas catarinense como mecanismo de promoção e estímulo ao uso da $\mathrm{EaD}$ como proposta educativa.

Palavras-chave: Formação Docente. Educação a Distância. Qualidade.

\begin{abstract}
The Teacher training is an important factor in the struggle for quality education in Brazil. The promulgation of the LDB in 1996, has the challenge of training new teachers, and it occurs at Distance Education a great alternative for access to public higher education. The DL is defined as educational approach that uses technology to bridge the gap between IES and students, and in this context appears the Open University of Brazil (UAB), currently the main policy of teacher education through distance education. The purpose is to provide teacher training policies included in the state of Santa Catarina, and detailed the UAB in the Brazilian and catarinense and analyzed the inclusion of TIC'S in schools in Santa Catarina as a mechanism to promote and encourage the use of distance education as an educational proposal.
\end{abstract}

Key words: Teacher training. Distance Education. Quality. 


\section{INTRODUÇÃo}

No processo de universalização e democratização do ensino, especialmente no Brasil, que atualmente pode ser caracterizado por apresentar déficits de professores e desigualdades na oferta de cursos para formação docente em cada estado da federação, deve-se considerar a modalidade a distância como uma alternativa de ensino que ofereça soluções efetivas à crescente demanda de professores que desejam uma formação de melhor qualidade e, consequentemente, propiciar um melhor ensino e oportunidades de acesso à educação superior aos alunos da rede básica.

O estímulo à oferta de cursos a distância, principalmente por parte do País após a criação da Lei de Diretrizes e Base (LDB) em 1996, da Educação Nacional, fez surgir inúmeros cursos nessa modalidade, em especial aqueles voltados à formação docente, ou seja, para professores carentes por uma formação acadêmica de nível superior.

Sendo assim, observa-se na EaD uma modalidade de ensino que pode contribuir diretamente com a formação de professores e, para isso, duas metas foram definidas pelo País (ANDIFES, 2003): formar 50.000 professores, particularmente nos campos disciplinares que apresentam maior déficit; e criar um programa para titular 250.000 professores que atuem nas redes estaduais e municipal.

A princípio, verifica-se nessas metas um recorte quantitativo da educação para a expansão da sua oferta, contudo, deve-se valorizar o aspecto qualitativo da oferta de cursos a partir do aumento permanente da sua eficácia institucional e efetividade acadêmica e social e, especialmente, na promoção do aprofundamento dos compromissos e responsabilidade sociais das instituições da educação superior, por meio da valorização de sua missão pública, da promoção dos valores democráticos, do respeito à diferença $e$ à diversidade, da afirmação da autonomia e da identidade institucional. (MEC, 2005)

Por fim, tem-se na qualidade da formação docente um aspecto preocupante e que assola a educação básica brasileira, e entendendo que a formação desses professores é decisiva para melhorar os índices da educação no país, será apresentado o sistema Universidade Aberta do Brasil como política de formação acadêmica, principalmente a de docentes.
No tocante ao cenário educativo da rede básica de Santa Catarina, apresentam-se como objetivos do trabalho analisar dados no que concerne à oferta de cursos de licenciatura, a exemplo do sistema UAB inserido no estado; e apresentar informações da infraestrutura tecnológica presente nas escolas da rede básica catarinense, que servem de apoio e estímulo ao uso da Educação a Distância pelos professores no processo de aprendizagem dos alunos.

\section{Formação do Docente}

O Brasil dispõe de uma carência na formação de professores, principalmente da educação básica, o que facilita o surgimento de políticas para ampliação na oferta de vagas na modalidade a distância. (CASTRO; AQUINO; ANDRADE; 2009)

Uma das tendências da formação docente é a aquisição da competência para atuar na educação a distância, e esse é, talvez, o maior dos desafios para a adoção da EaD. De acordo com Sousa (1996), o aparato tecnológico necessário, ainda que de alto custo, pode ser facilmente adquirido. As barreiras estão na utilização eficaz desse aparato, sobretudo, porque será necessário superar comportamentos e procedimentos tradicionais de ensino muito arraigados.

Dessa forma, segundo Belloni (2006), o papel que o professor assume na $\mathrm{EaD}$ é o de parceiro do estudante no processo de construção do conhecimento, ou seja, acontece a transformação do professor de uma entidade individual em uma entidade coletiva, cujo o foco deixa de ser o ensino para ser a aprendizagem.

A EaD tende a se tornar, cada vez mais, um elemento regular e necessário aos sistemas educativos, não somente para atender demandas específicas, mas também para estabelecer-se como função de grande importância, especialmente na educação da população adulta, pela demanda crescente aos cursos supletivos, formação continuada (life long learning) e pós-graduação. (VIANNEY; BARCIA; LUZ, 2010)

Por um lado, esse contexto justifica a necessidade de uma formação mais consistente, contudo flexível para diagnosticar contextos e criativa para atuar adequadamente. Por outro lado, explicita que é uma profissão que implica saberes e que um processo formativo consequente demanda compreender como 
esses saberes são produzidos, integrados e utilizados na prática profissional. (GUIMARÃES, 2004)

Uma aprendizagem apropriada das Tecnologias da Informação e Comunicação (TICs), de modo a prover uma visão integral da disciplina, e pôr ênfase na "cultura da informação", é um elemento-chave no êxito da preparação dos docentes. (OILO, 1998)

Formar docentes para atuar em educação a distância é, também para Rezende (2010), a chave na implementação dessa modalidade, principalmente quando se almeja mudança na qualidade na aprendizagem.

A mudança requerida é muito mais ampla $e$ complexa e exige a compreensão pedagógica do processo de ensino e aprendizagem mediada, além de demandar o desenvolvimento de competências e habilidades especiais dos docentes $e$, porque não dizer, dos alunos. Em particular, a educação a distância exige que o docente saiba como transpor sua prática do real para o virtual. (REZENDE, 2010)

Como exposto anteriormente, o uso das tecnologias de $\mathrm{EaD}$ implica uma mudança radical: do ensino centrado no professor para o ensino centrado no aluno, o que, para muitos, parece uma diminuição do papel do professor, que passaria a ser um simples facilitador do processo de aprendizagem. Enfim, é o velho receio de que o professor seja substituído pelos meios e pela máquina. (SOUSA, 1996)

De forma complementar, Pimenta e Anastasiou (2005) aportam que o professor neste cenário precisa refletir constante e coletivamente sobre o que se faz $e$ isso é colocar-se na roda, é deixar-se conhecer, é expor-se. Os autores também afirmam que é essencial considerar a importância da criatividade na solução de cada nova situação vivenciada. Nesse sentido, a aula - como momento e espaço privilegiado de encontro e de ações (seja presencial ou a distância) - não deve ser dada nem assistida, mas construída, feita pela ação conjunta de professores e alunos.

No Brasil, a primeira experiência de formação inicial de professores para o ensino básico por meio da educação a distância foi a licenciatura de pedagogia criada pela Universidade Federal do Mato Grasso, em 1995, com parceria do estado e municípios (Licenciatura Plena em Educação Básica: $1^{\mathrm{a}}$ a $4^{\mathrm{a}}$ série do $\mathbf{1}^{\circ}$ grau). (BELLONI, 2006)
Sumarizando, para Rezende (2010), a questão principal para o professor on-line é a consciência de que ele deverá se preparar para desenvolver o conhecimento pedagógico (teorias de aprendizagem) que o capacite a atuar como instrumento auxiliar de ensino e aprendizagem, usando o computador como suporte; adquirir consistência teórica dos conteúdos disciplinares a serem ensinados; e aprender, gradativamente, a transpor sua prática do real ao virtual, realizando experiências concretas, dotado de postura reflexiva na e sobre a ação, não aceitando modelos prontos e acabados.

Dessa maneira, Moraes (2010) destaca que as implicações do novo paradigma na formação dos futuros professores para uma sociedade do conhecimento precisam ser cuidadosamente observadas visando um redimensionamento de seu papel. O modelo de formação dos professores pressupõe continuidade e visão de processo, não buscando um produto completamente acabado e pronto, mas um movimento permanente de "vir a ser". É um movimento de reflexão na ação e de reflexão sobre a ação.

Demonstrada a importância da formação docente, de maneira inicial e continuada, como forma de preparar os professores para atuar na rede básica de ensino, será apresentada a Educação a Distância como modalidade de ensino eficaz na formação de docentes.

\subsection{Educação a Distância}

A educação a distância é uma modalidade de ensino/aprendizagem na qual o instrutor e o aluno estão afastados no espaço e, muitas vezes, no tempo. Dentre as definições disponíveis na literatura, pode-se escolher a de Moore e Kearsley (2007, p. 1):

A idéia básica de educação a distância é muito
simples: alunos e professores estão em locais
diferentes durante todo ou grande parte do
tempo em que aprendem e ensinam. Estando
em lugares distintos, eles dependem de algum
tipo de tecnologia para transmitir informações
e lhes proporcionar um meio para interagir.

A clara e simples definição apresentada pelos autores estabelece os três elementos principais que sempre estiveram presentes no contexto da $\mathrm{EaD}$ : alunos, professores e o meio responsável pela aproximação e interação deles. Hodiernamente, o aluno 
continua afastado do professor, mas foi introduzido o ator institucional "Tutor" como auxiliar do professor no processo de ensino-aprendizagem, acompanhando o aluno remota e presencialmente. Também o meio utilizado para aproximação evoluiu, das cartas aos telecursos, passando pela telepresença e, atualmente, tomando a forma dos meios que utilizam a internet, tendo entre seus expoentes o Moodle, o Blackboard, Angel e Sakai.

A utilização da EaD por instituições de ensino não é de longa data. No final do século XIX instituições particulares nos EUA e na Europa ofereciam cursos por correspondência destinados ao ensino de temas e de problemas vinculados a ofícios de escasso valor acadêmico (LITWIN, 2001). Em 1892, por exemplo, a universidade de Chicago instituiu um curso por correspondência, e no início do século $\mathrm{XX}$, a instituição de ensino Calvert, em Baltimore, desenvolveu curso nessa modalidade para a escola primária. Em 1930 já era possível identificar 39 universidades norte-americanas que ofereciam cursos a distância.

Contudo, somente na década de 1960 a universidade a distância começou a competir com a universidade presencial, principalmente após a implantação da universidade Aberta da Grã-Bretanha, mais conhecida por Open University, que desenvolveu uma proposta de educação com um desenho complexo, na qual eram utilizados meios impressos e televisivos para oferta de cursos intensivos em períodos de recesso de outras universidades convencionais. (LITWIN, 2001)

Moore e Kearsley (2007) organizam a história da modalidade em cinco gerações: a primeira baseada em correspondência postal; a segunda baseada em transmissão dos programas educativos por rádio $e$ televisão; a terceira com o surgimento das universidades abertas; a quarta com a evolução das tecnologias de comunicação até o ponto das teleconferências; $e$, atualmente, a quinta geração, com o uso da internet $e$ da World Wide Web.

O autores traçam também um panorama histórico da EaD como uma modalidade de estudo que evolui em sua forma, conteúdo e regulação, na medida em que as tecnologias de comunicação tornam possível um próximo passo. Isso leva a inevitável conclusão de que não se chegou, ainda, ao formato definitivo de aplicação da $\mathrm{EaD}$, configurando-a como uma metodologia em franca evolução.

No Brasil, a história pode ser dividida em dois períodos, pré e pós-Lei de Diretrizes e Bases (LDB) da Educação Brasileira, Lei n. 9.394, de 1996, visto que essa lei apresentou para a sociedade um marco regulatório para a modalidade a distância, em que pela primeira vez na história da legislação ordinária o tema EaD se converte em objeto formal de análise. (VIANNEY; TORRES; SILVA, 2003)

No período anterior à LDB existiam muitas resistências e preconceitos quanto à Educação a Distância, contudo,

[...] a atual conjuntura encontrou nesta modalidade uma alternativa economicamente viável, uma opção às exigências sociais e pedagógicas, contando com o apoio do avanço das novas tecnologias da informação e comunicação. (PRETI, 2009, p. 26).

A EaD nasceu e se desenvolveu como resposta a um acúmulo importante de necessidades educacionais, como estas: alfabetização, incorporação cada vez mais precoce ao mundo do trabalho, população isoladas dos centros urbanos ou impossibilidade de ter acesso, por diversos motivos, às formas convencionais de ensino. (LITWIN, 2001)

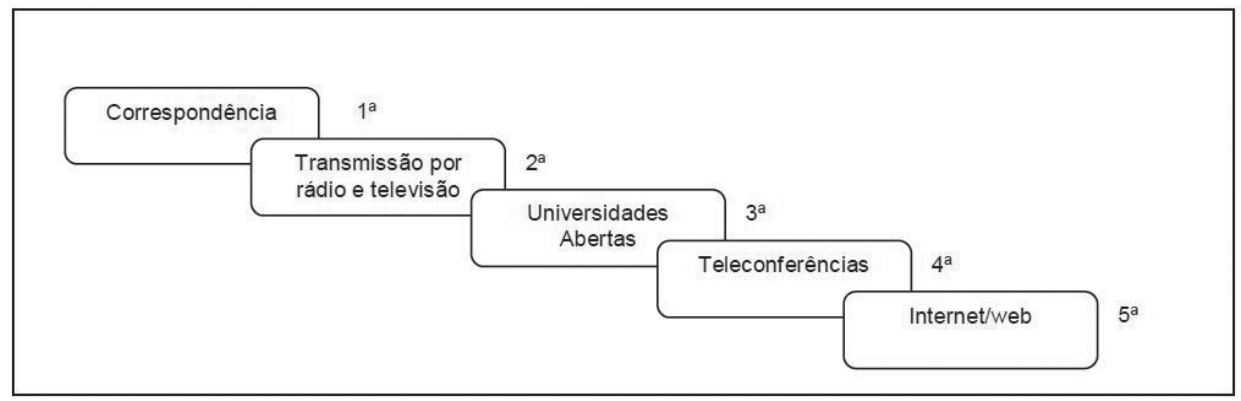

Figura 1: Cinco gerações de educação a distância

Fonte: Moore e Kearsley (2007, p. 26) 
Contextualizada a EaD no Brasil até a criação da LDB, Vianney, Torres e Silva (2003) destacam ainda que o MEC, em 1997, formou um grupo de especialistas para criar a regulamentação do artigo 80 da LDB, tendo como resultado a criação de várias legislações - Decretos n. 2.494 e n. 2.561; Portaria n. 301 e Resolução n. 1. Contudo, somente em 2005, com a criação do Decreto n. 5.622 e da Universidade Aberta do Brasil (UAB), o Brasil pôde traçar objetivos maiores com a EaD e configurar o cenário que hoje se apresenta na educação.

O período pós-LDB pode ser caracterizado pelo uso intenso da informática na educação brasileira, que, segundo Andrade e Lima (1993), se fortaleceu com a realização do I Seminário de Informática na Educação, na Universidade de Brasília, e a aprovação do documento intitulado Subsídios para a Implantação do Programa Nacional de Informática na Educação, em 1981. Esse documento foi desenvolvido pelo Ministério da Educação (MEC) juntamente com a Secretaria Especial de Informática (SEI), Conselho Nacional de Desenvolvimento Científico e Tecnológico (CNPq) e Financiadora de Estudos e Projetos (FINEP).

No documento recomendava-se, por exemplo, que estudos voltados à utilização da informática na educação deveriam ser conduzidos pelas universidades, pois era necessário construir, primeiramente, conhecimentos técnico-científicos, para depois debatê-los na comunidade nacional.

A utilidade da EaD surge no contexto educacional como ferramenta de combate a um acúmulo de importantes necessidades educacionais: alfabetização; necessidade do estudante ingressar no mercado de trabalho de modo precoce; e população isolada dos centros urbanos ou impossibilitadas ao acesso do ensino convencional. (LITWIN, 2001)

Quanto à sistematização da EaD, pode-se dizer que modalidade a distância se desenvolve a partir de um sistema tecnológico de comunicação bidirecional, que substitui o contato pessoal professor/estudante como meio preferencial de ensino por ações sistemáticas e conjuntas de diversos recursos didáticos e um Sistema de Acompanhamento ao Estudante. Tais sistemas possibilitam a aprendizagem independente $e$ flexível dos acadêmicos. (ARETIO, 1996)

Diante dessa realidade, pode-se verificar diferentes ações que são aplicadas à $\mathrm{EaD}$ por gestores educacionais com o objetivo de melhorar a qualidade dos cursos: proporcionar oportunidades para atualizar aptidões; melhorar a redução de custos dos recursos educacionais; apoiar a qualidade das estruturas educacionais existentes; melhorar a capacitação do sistema educacional; nivelar desigualdades entre grupos etários; proporcionar treinamento de emergência para grupos-alvo importantes; aumentar as aptidões para a educação em novas áreas de conhecimento; oferecer uma combinação de educação com trabalho e vida familiar; e agregar uma dimensão internacional à experiência educacional. (MOORE, KEARSLEY, 2007)

Com base nessas ações, verifica-se também a necessidade dos gestores elaborarem um planejamento coerente de cursos a distância, sendo que algumas perguntas precisam ser respondidas a fim de se obter o sucesso pretendido (MOORE, KEARLEY, 2007):

- Quais são as características das diferentes tecnologias de comunicação e das mídias e como podem ser usadas na educação a distância?

- Quais mídias e tecnologias de comunicação são as melhores para uma determinada disciplina ou um grupo de alunos?

- De que modo mídia e tecnologias podem ser combinadas para se obtenha eficácia máxima?

As respostas dessas perguntas permitem aos gestores um melhor posicionamento quanto aos objetivos que se pretende alcançar e, a partir disso, é preciso definir alguns critérios de qualidade na configuração e no planejamento do curso.

Muitos são os detratores da educação a distância por considerá-la um método secundário, uma espécie de "último recurso" àqueles que não podem, por razões diversas, cursar o ensino presencial, acabam por repudiar a modalidade, promovendo muitas vezes uma imagem equivocada da $\mathrm{EaD}$, e assim afastando muitas pessoas que poderiam buscar uma melhor formação acadêmica. É importante destacar que utilização de diferentes métodos de ensino, recursos, ferramentas e tecnologias aplicados à otimização do ensino presencial faz pensar que a EaD preserva todas as qualidades de uma boa educação, o que permite às pessoas desenvolver suas capacidades cognitivas, sociais, emocionais, profissionais e éticas; e viver em sociedade, exercitando sua cidadania plena. (MEC, 2010) 


\subsection{Políticas de Acesso à Educação}

O Governo Federal vem desenvolvendo diversos programas institucionais que utilizam a modalidade a distância com a finalidade de capacitar e desenvolver professores da educação básica e, consequentemente, melhorar o ensino dos estudantes. No cenário brasileiro foram lançados os seguintes programas: Um Salto para o Futuro, em 1991, TV Escola, em 1996, o Programa Nacional de Informática na Educação (ProInfo), em 1997; o Programa de Formação de Professores em Exercício (Proformação), em 1997; o Programa de Apoio à Pesquisa em Educação a Distância (PAPED), em 1997; o Pró-Licenciatura, em 2005; a Universidade Aberta do Brasil (UAB), em 2005, que será apresentada na análise dos dados mais profundamente em razão de representar o principal programa de formação docente a distância no Brasil; e o Plano Nacional de Formação dos Professores da Educação Básica (PARFOR), em 2009.

O entendimento de Formação Continuada de professores, presente no Estado de Santa Catarina, caracteriza-se por um processo de formação que associa diferentes tipos e modalidades de estudos, de forma que o professor possa, coletiva ou individualmente, adquirir novos conteúdos, competências e habilidades. Dessa forma, a formação continuada visa ampliar e qualificar a aprendizagem dos estudantes por meio do aperfeiçoamento da formação e da prática pedagógica do professor, sendo que a principal razão para que a Secretaria do Estado de Educação trace uma política para formar profissionais deve-se à constatação de que nenhum sistema educacional poderá alcançar qualidade na educação básica sem que seus professores e gestores tenham uma formação inicial e continuada de qualidade (SED-SC, 2010).

Em Santa Catarina registra-se o apoio do governo aos programas de formação continuada a distância: Um Salto para o Futuro e TV Escola, criados em 1991 e 1996, respectivamente em nível nacional. Outra interessante proposta, sendo essa mais recente, de 2008, diz respeito à criação de um espaço virtual que estimule a construção $e$ a utilização de conteúdos e de recursos pedagógicos na prática do ensino, principalmente no que se refere às TICs. Essa proposta foi apoiada pela Secretaria de Estado da Educação e designada como Ambiente Pedagógico Colaborativo (APC), pois através desse ambiente os educadores têm à sua disposição conteúdos produzidos por seus pares, referentes às diversas disciplinas do Ensino Fundamental e Médio, podendo ser utilizados como suporte teórico para a elaboração de suas aulas. Esses conteúdos estão disponíveis por meio de recursos, como estes: indicação de textos, livros, filmes, fotos, sítios eletrônicos, propostas de atividades e reflexões sobre o conteúdo proposto. (SED-SC, 2010)

O APC possibilita também a pesquisa, a consulta e a troca de experiências para subsidiar a prática pedagógica do professor por meio de um modelo de colaboração no qual os educadores da Rede Pública de Educação Básica do Estado de Santa Catarina podem potencializar seus conhecimentos pelo acesso aos conteúdos elaborados por seus pares e, ao mesmo tempo, divulgarem sua produção intelectual.

Sumarizando, para Rezende (2010), a questão principal para o professor on-line é a consciência de que ele deverá se preparar para:

- desenvolver o conhecimento pedagógico (teorias de aprendizagem) que o capacite a atuar como instrumento auxiliar de ensino $e$ aprendizagem, usando o computador como suporte;

- adquirir consistência teórica dos conteúdos disciplinares a serem ensinados; $e$

- aprender, gradativamente, a transpor sua prática do real para o virtual, realizando experiências concretas, dotado de postura reflexiva na e sobre a ação, não aceitando modelos prontos e acabados.

Dessa maneira, Moraes (2010) destaca que as implicações do novo paradigma na formação dos futuros professores para uma sociedade do conhecimento precisam ser cuidadosamente observadas visando um redimensionamento de seu papel. O modelo de formação dos professores pressupõe continuidade e visão de processo, não buscando um produto completamente acabado e pronto, mas um movimento permanente de "vir a ser". É um movimento de reflexão na ação e de reflexão sobre a ação.

Demonstrada a importância da formação docente, de maneira inicial e continuada, seja ela presencial ou a distância, como critério essencial à melhoria da qualidade no ensino das pessoas, será retratado a seguir a metodologia utilizada no desenvolvimento do trabalho e as principais análises que dizem respeito à 
formação docente no Brasil, mais detalhadamente o cenário catarinense.

\section{Procedimentos Metodológicos}

O método de pesquisa é o conjunto das atividades sistemáticas e racionais que, com maior segurança $e$ economia, permite alcançar os objetivos - conhecimentos válidos e verdadeiros, de modo a traçar o melhor caminho a ser percorrido, detectando erros $e$ auxiliando nas decisões do cientista. (LAKATOS, MARCONI, 2004)

As informações contidas neste trabalho foram sistematizadas e refletem o cenário da educação básica catarinense no espaço temporal de 2007 a 2010, de modo a apresentar séries históricas para estabelecer comparações de evolução.

O trabalho é do tipo exploratório, pois a partir dos objetivos definidos foram feitos levantamentos bibliográficos de temas específicos e inerentes à formação docente; e da análise dos dados extraídos do banco de dados disponibilizado pelo INEP e UAB.

Este trabalho caracteriza-se ainda também como não experimental e quali-quantitativo, em razão de terem sido feitas análises qualitativas por meio da temática proposta e, também, quantitativas de dados coletados do banco de dados do INEP e da UAB, utilizando-se gráficos e tabelas.

\section{Apresentação e Análise dos Dados}

A interpretação, a explicação e a especificação dos dados coletados consistem nos três níveis da elaboração desta análise e, por meio deles, busca-se fazer as relações necessárias entre os dados obtidos com o estudo proposto e a teoria analisada. Sendo assim, serão apresentados dados referentes à oferta de cursos de licenciatura no Brasil, e mais especificamente em Santa Catarina. Num segundo momento é caracterizado o Sistema UAB no que permeia cursos de licenciatura no Brasil e em SC; e, por fim, são apresentados dados da situação das escolas da rede básica catarinenses no tocante ao número de computadores e no acesso à internet, visto que essas informações podem identificar a possibilidade do uso da modalidade a distância de docentes e de alunos da rede básica.

\subsection{Ofertas de Cursos de Licenciatura em SC}

No Brasil, o total de cursos a distância disponibilizados à população em 2007 era de 1.181, sendo 351 cursos de graduação, 87 cursos de tecnólogos, 404 cursos de especialização, 1 de mestrado, 150 de extensão e aperfeiçoamento, 73 de técnicos e 115 cursos de Educação de Jovens e Adultos (EJA)(ABRAEAD, 2010). Dentre os 351 cursos de graduação identificados, 210 cursos eram licenciaturas, divididos por região da seguinte maneira (Tabela 1):

Tabela 1: Oferta de cursos de licenciatura modalidade EaD, no Brasil, por região

\begin{tabular}{|l|c|}
\hline \multicolumn{2}{|c|}{$\begin{array}{c}\text { Total De cursos DE Licenciatura EAD POR } \\
\text { REGião }\end{array}$} \\
\hline Norte & 5 \\
\hline Nordeste & 54 \\
\hline Centro-Oeste & 22 \\
\hline Sudeste & 81 \\
\hline Sul & 48 \\
\hline Total & 210 \\
\hline
\end{tabular}

Fonte: ABRAEAD (2010)

É importante salientar que os 210 cursos de licenciatura representam cursos individuais oferecidos pelas instituições, e não dos polos presenciais, uma vez que o curso pode ser oferecido a um ou a mais polos, permitindo assim o acesso de vários estudantes. No caso de Santa Catarina, podem ser identificados 15 cursos de licenciatura (Tabela 2).

Tabela 2: Cursos de licenciatura EaD no Estado de SC

\begin{tabular}{|l|c|}
\hline \multicolumn{2}{|c|}{$\begin{array}{c}\text { Licenciaturas EaD em Santa Catarina - CENSO } \\
\text { Educhão Superior 2007 }\end{array}$} \\
\hline \multicolumn{1}{|c|}{ Curso } & Total \\
\hline Licenciatura em Geografia (EaD) & 2 \\
\hline Licenciatura em História (EaD) & 1 \\
\hline $\begin{array}{l}\text { Licenciatura em Letras - Língua } \\
\text { Portuguesa e Literatura (EaD) }\end{array}$ & 1 \\
\hline Licenciatura em Matemática (EaD) & 4 \\
\hline Licenciatura em Ciências Biológicas (EaD) & 1 \\
\hline Licenciatura em Física (EaD) & 1 \\
\hline Licenciatura em Letras - Língua & 1 \\
\hline Brasileira de Sinais (LIBRAS) & 4 \\
\hline Pedagogia (EaD) & 15 \\
\hline Total & \\
\hline
\end{tabular}

Fonte: Base de Dados INEP (2010) 
A tabela exibe a oferta de cursos de licenciatura na modalidade EaD em Santa Catarina, e, comparando o total de cursos de licenciatura EaD no Brasil, verifica-se que o estado catarinense é responsável por $7,14 \%$ deles, e em sua regiãoesse valor corresponde a $31,25 \%$.

\subsection{Universidade Aberta do Brasil (UAB)}

A importância da formação docente por meio de cursos a distância fez com que o Estado brasileiro incentivasse os seus docentes, principalmente aqueles situados na educação básica, a buscar uma formação superior de melhor qualidade e, nesse contexto, surge em 2005 a Universidade Aberta do Brasil (UAB), que se refere a um sistema integrado por universidades públicas que oferece cursos de nível superior para camadas da população que têm dificuldade de acesso à formação universitária, por meio do uso da modalidade de educação a distância.

O público em geral é atendido, mas os professores que atuam na educação básica têm prioridade de formação, seguidos dos dirigentes, gestores e trabalhadores em educação básica dos estados, dos municípios e do Distrito Federal. (CAPES, 2011)

A UAB se refere a cursos a distância oferecidos por instituições públicas federais, sendo que a operacionalização do curso apenas é possível em razão da existência de polos de apoio presencial. Esses polos se referem à estrutura física, de responsabilidade dos municípios que têm por função acolher os estudantes no momento das atividades presenciais, obrigatórias na UAB e dizem respeito às provas ou seminários organizados pelos professores dos cursos.

Os primeiros cursos da UAB foram oferecidos já em 2005, mas é a partir de 2007 que é possível identificar uma adesão maior das universidades pela oferta de cursos na modalidade a distância, sendo que a evolução dos cursos de 2007 a 2010 é observada pela Figura 2.

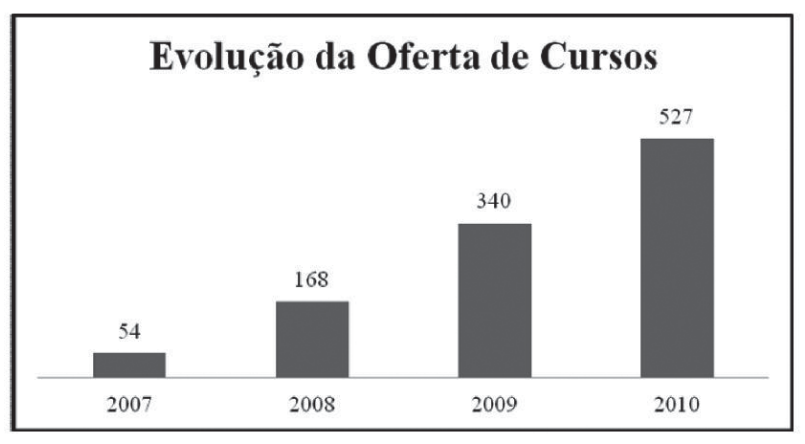

Figura 2: Evolução de cursos EaD no sistema UAB no Brasil Fonte: SISUAB (2011)

O sistema UAB é entendido como um importante meio de acesso à educação superior no Brasil, a exemplo dos dados apresentados na Figura 2, que demonstram uma expansão de aproximadamente $1.000 \%$ em quatro anos. Já a oferta de cursos para Santa Catarina no ano de 2010 é exposta na Tabela 3:

Tabela 3: Cursos UAB em Santa Catarina em 2010

\begin{tabular}{|l|l|l|}
\multicolumn{1}{|c|}{ Nome Do CURSo } & \multicolumn{1}{|c|}{ TIPO DE CURSo } & \multicolumn{1}{c|}{ IES } \\
\hline Administração Pública & Bacharelado & UFSC \\
\hline Ciências Biológicas & Licenciatura & UFSC \\
\hline $\begin{array}{l}\text { Controle da gestão } \\
\text { Pública Municipal }\end{array}$ & Lato Sensu & UFSC \\
\hline $\begin{array}{l}\text { Educação de } \\
\text { Jovens e Adultos }\end{array}$ & Aperfeiçoamento & IF-SC \\
\hline $\begin{array}{l}\text { Educação Integral } \\
\text { e Integrada }\end{array}$ & Aperfeiçoamento & UFSC \\
\hline $\begin{array}{l}\text { Educaçãa para a } \\
\text { Diversidade e Cidadania }\end{array}$ & Extensão & UFSC \\
\hline Ensino de Ciências & Lato Sensu & UFSC \\
\hline Filosofia & Licenciatura & UFSC \\
\hline Física & Licenciatura & UFSC \\
\hline $\begin{array}{l}\text { Formação de Professores } \\
\text { em Matemática }\end{array}$ & Lato Sensu & UFSC \\
\hline $\begin{array}{l}\text { Formação Professor } \\
\text { de Tradução }\end{array}$ & Lato Sensu & UFSC \\
\hline $\begin{array}{l}\text { Gênero e Diversidade } \\
\text { na Escola }\end{array}$ & Aperfeiçoamento & UFSC \\
\hline $\begin{array}{l}\text { Gestão de Bibliotecas } \\
\text { Escolares }\end{array}$ & Lato Sensu & UFSC \\
\hline $\begin{array}{l}\text { Gestão em Tecnologias } \\
\text { na Educação }\end{array}$ & Lato Sensu & IF-SC \\
\hline Gestão Pública & Lato Sensu & IF-SC \\
\hline Letras Espanhol & Lato Sensu & UFSC \\
\hline
\end{tabular}




\begin{tabular}{|l|l|l|}
\hline Letras Inglês & Licenciatura & UFSC \\
\hline Letras Português & Licenciatura & UFSC \\
\hline Matemática & Licenciatura & UFPEL \\
\hline Pedagogia & Licenciatura & UFSC \\
\hline
\end{tabular}

Fonte: SISUAB (2011)

No que diz respeito, exclusivamente, à oferta de curso de licenciatura no sistema UAB pelo Estado, são identificados sete cursos, concentrados na Universidade Federal de Santa Catarina (UFSC) e no Instituto Federal de Santa Catarina (IF-SC). Para que se possa fazer uma comparação com o total de cursos de licenciatura no Brasil e na Região Sul, apresenta-se a evolução de licenciaturas de 2007 a 2010 nesses dois contextos.

\section{Cursos de Licenciatura}

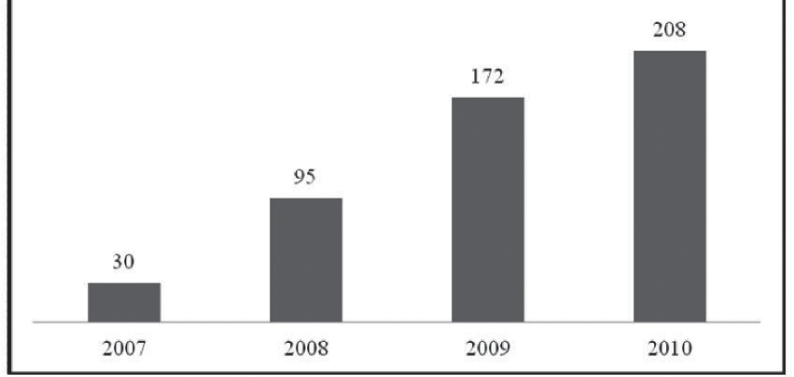

Figura 3: Evolução dos cursos de Licenciatura no Brasil Fonte: SISUAB (2011)

Considerando somente a Região Sul do Brasil, uma vez que o estado catarinense se encontra nessa região, verifica-se a seguinte evolução dos cursos de licenciatura no Programa UAB:

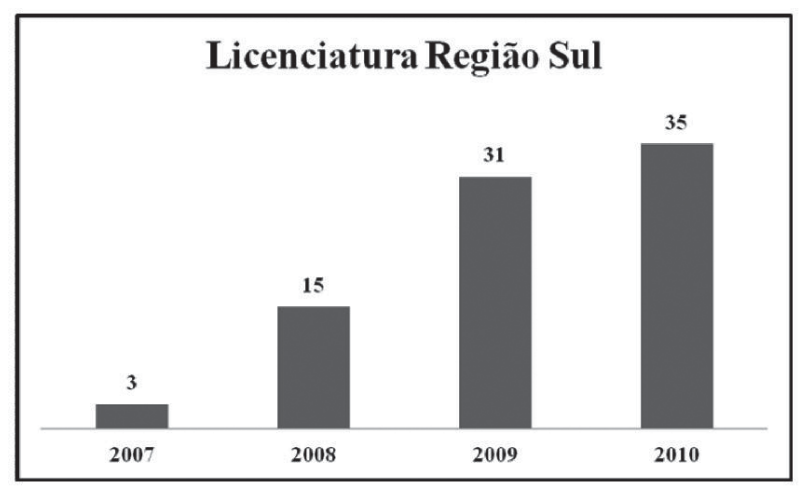

Figura 4: Evolução dos cursos de Licenciatura na Região Sul Fonte: SISUAB (2011)
Sendo assim, identifica-se um total de 208 cursos de licenciatura no Brasil em 2010, e desses, 35 são da Região Sul. Fazendo um comparativo com os cursos oferecidos por SC, sete, verifica-se que o estado é responsável pela oferta de 3,3\% e $20 \%$ dos cursos no Brasil e na Região Sul, respectivamente. Esses dois valores, numa análise apenas numérica, representam uma quantidade pequena de cursos, contudo, sabendo-se que são apenas duas as instituições catarinenses inseridas na $\mathrm{UAB}$, e que a população do estado corresponde a aproximadamente $3 \%$ da população do Brasil, 6 milhões de habitantes, é possível dizer que o estado tem uma representatividade considerável no que concerne à oferta de cursos de licenciatura EaD por meio da UAB. Prospectando-se a oferta de cursos de licenciatura por meio do programa, além do aumento de cursos e de vagas, deve-se priorizar a melhoria da qualidade dos cursos já oferecidos com a inserção de novas tecnologias na dinâmica dos cursos e, também, no local de trabalho desses professores, ou seja, na sala de aula.

\subsection{Inserção das TICs na Educação Básica}

A inserção das TICs na educação básica é um passo importante para garantir que a educação ofertada aos alunos seja atualizada e realmente possa prepará-los para o competitivo mercado de trabalho da economia do século XXI.

No intuito de se aferir a penetração das TICs na educação básica em Santa Catarina, buscou-se dados do INEP quanto à presença de computadores nas escolas. O número total de computadores nas escolas não indica acesso às plataformas de $\mathrm{EAD} e$, por isso, o INEP investiga quantos desses computadores são destinados ao uso administrativo e quantos estão disponíveis aos alunos.

$\mathrm{Na}$ Tabela 4 exibe-se a quantidade de computadores acessíveis aos alunos nas escolas por mesorregião catarinense: 
Tabela 4: Computadores para uso dos alunos na rede básica de SC por mesorregião, em 2008

\begin{tabular}{|l|c|}
\hline \multicolumn{1}{|c|}{ MesoRREGIÃo } & QuANTIDADE \\
\hline Grande Florianópolis & 52.431 \\
\hline Norte & 75.297 \\
\hline Oeste & 71.875 \\
\hline Serrana & 16.202 \\
\hline Sul & 45.489 \\
\hline Vale do Itajaí & 74.452 \\
\hline Total & 335.746 \\
\hline
\end{tabular}

Fonte: Base de Dados INEP (2010)

Logo, apresenta-se uma tabela com o número de computadores disponíveis ao uso administrativo. Essa disposição indica a atualização na administração escolar e, embora sua disponibilidade não seja aos alunos, o uso desses computadores permite que professores e diretores acessem as plataformas e os ambientes virtuais de aprendizagem e façam o acompanhamento de seus alunos.

Tabela 5: Quantidade de computadores para uso administrativo nas escolas da rede básica de SC por mesorregião, em 2008

\begin{tabular}{|l|c|}
\hline \multicolumn{1}{|c|}{ MeSORREGIÃo } & QuANTIDADE \\
\hline Grande Florianópolis & 2.293 \\
\hline Norte & 3.391 \\
\hline Oeste & 2.580 \\
\hline Serrana & 746 \\
\hline Sul & 2.187 \\
\hline Vale do Itajaí & 3.202 \\
\hline Total & 14.399 \\
\hline
\end{tabular}

Fonte: Base de Dados INEP (2010)

Tendo sido demonstrada a presença de computadores nas escolas, na qual se observa uma maior concentração na região norte, região que possui a maior cidade catarinense, Joinville, faz-se necessário saber quantos e em que proporção as escolas da rede básica estão conectadas à rede mundial de computadores.
A tabela a seguir exibe a disponibilidade de acesso à internet nas escolas básicas de Santa Catarina, de acordo com a dependência administrativa:

Tabela 6: Disponibilidade de internet em escolas da rede básicas de SC, por dependência administrativa, em 2008

\section{DISPONIBILIDADE DE INTERNET NAS ESCOLAS BÁSICAS POR DEPENDÊNCIA ADMINISTRATIVA}

\begin{tabular}{|c|c|c|c|}
\hline \multirow{2}{*}{$\begin{array}{l}\text { DEPENDÊNCIA } \\
\text { AdMINISTRATIVA }\end{array}$} & \multicolumn{3}{|c|}{ Possui ACESSO À INTERNET? } \\
\hline & NÃo & SIM & \%SIM \\
\hline Federal & 0 & 10 & $100,00 \%$ \\
\hline Estadual & 207 & 1.047 & $83,49 \%$ \\
\hline Municipal & 1.664 & 953 & $36,42 \%$ \\
\hline Privada & 142 & 769 & $84,41 \%$ \\
\hline Total & 2.013 & 2.779 & $57,99 \%$ \\
\hline
\end{tabular}

Fonte: Base de Dados INEP (2010)

Ao observar os dados disponibilizados, percebe-se que $100 \%$ das escolas básicas da rede federal de ensino dispóem de acesso à internet, contudo Santa Catarina conta apenas com dez escolas nessa categoria. Nas redes estadual e privada, a penetração do acesso à rede mundial de computadores está praticamente no mesmo patamar, próximo a $85 \%$. A rede municipal, entretanto, segue muito atrás com a penetração do acesso de $36,42 \%$.

No total de escolas da rede básica, no total de 4.792, apresenta-se a proporção de escolas com acesso à internet.

Tabela 7: Disponibilidade de internet em escolas básicas em SC, dados consolidados, 2007

\section{DISPONIBILIDADE DE INTERNET NAS ESCOLAS BÁSICAS POR DEPENDÊNCIA ADMINISTRATIVA E MICRORREGIÃO}

\begin{tabular}{|l|c|c|}
\hline \multicolumn{1}{|c|}{ RESUMo } & FREQUÊNCIA & \% \\
\hline Total de Escolas Básicas & 4.792 & $100 \%$ \\
\hline Acessam a internet & 2.779 & $57,99 \%$ \\
\hline Não Acessam a internet & 2.013 & $42,01 \%$ \\
\hline
\end{tabular}

Fonte: Base de Dados INEP (2010)

Fazendo a distribuição das escolas da rede básica nas regiões catarinense, é possível apresentar o mapa de escolas com acesso à internet no estado (Figura 5). 


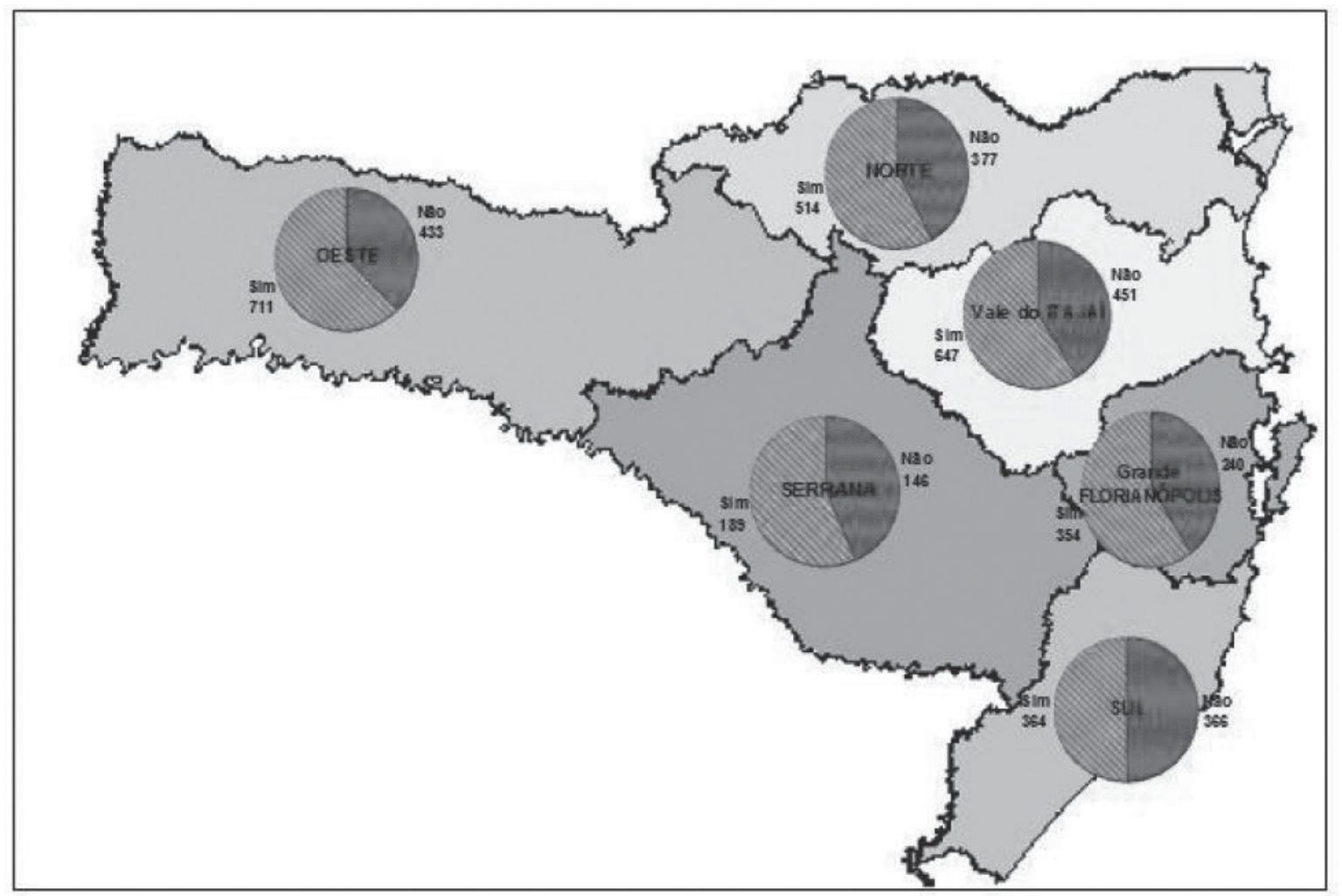

Figura 5: Disponibilidade de internet em escolas básicas do Estado de Santa Catarina, por mesorregião, em 2008 Fonte: Elaborado pelos autores deste artigo a partir da Base de Dados INEP (2010)

No mapa são exibidas as distribuições em cada mesorregiáo das escolas com e sem acesso, com seus números absolutos, sendo que na maioria das mesorregiões, excetuando-se a Região Sul, o acesso à internet nas escolas da rede básica é maior do que o acesso naquelas escolas que não o possuem.

\section{Considerações Finais}

Este artigo permite caracterizar a formação docente por meio da Educação a Distância como importante iniciativa para preparar e desenvolver o professor para o estímulo do aprendizado estudantil da rede básica como o uso das tecnologias de aprendizagem. Destaca-se ainda que o professor com formação na modalidade a distância certamente irá possuir maior familiaridade no uso de novas tecnologias de informação e comunicação, fazendo uso delas para uma melhor didática na sala de aula.

A constante inserção de computadores e a abrangência do acesso à internet nas escolas do estado de SC demonstram que a informática veio para ficar $e$ agregar formação específica aos alunos.
Tanto na formação docente como na aplicação das técnicas desenvolvidas para o ambiente $\mathrm{EaD}$ na sala de aula, diversas possibilidades se abrem - novos conteúdos são adaptados constantemente aos ambientes virtuais, ganha força o estudo não presencial, evidencia-se o dinamismo dos conteúdos multimídias, se expande a capacidade dos professores de acompanharem a frequência de estudo de seus alunos, enfim, uma nova e poderosa forma de conduzir o processo ensino-aprendizagem toma forma.

Por fim, registra-se que o estado de Santa Catarina certamente irá progredir em seus indicadores de qualidade da educação com o uso de tecnologias didáticas em salas de aula e de uma melhor formação docente advinda da $\mathrm{EaD}$, sendo o resultado desses dois fatores o aluno mais motivado e preparado para adentrar no mercado de trabalho.

\section{REFERÊNCIAS}

ABRAEAD. Anuário brasileiro estatístico de educação aberta e a distância. [2010?]. Disponível em: <http:// www.abraead.com.br/>. Acesso em: 17 jun. 2010. 
Rafael Pereira Ocampo Moré • Grace Tavares Vieira • Márcia Santiago de Araújo • Alexandre Marino Costa

ANDIFES, Associação Nacional de Dirigentes das Instituições Federais de Ensino Superior. Proposta de expansão e modernização do sistema público federal de ensino superior. Brasília, 2003.

ANDRADE, Pedro Ferreira; LIMA, Maria Candida Moraes de Albuquerque. Projeto educom. Brasília: MEC/OEA, 1993.

ARETIO, Lorenzo Garcia. Educación a distancia hoy. Madrid: Universidad Nacional de Educación a Distancia (UNED), 1996.

BELLONI, Maria Luiza. Educação a distância. São Paulo: Autores Associados, 2006.

CAPES. UAB - Universidade Aberta do Brasil.

[2011?]. Disponível em: <http://www.uab.capes.gov.br/ index.php>. Acessado em: 17 mar. 2011.

CASTRO, Jorge Abrahão de; AQUINO, Luseni Maria C. de; ANDRADE, Carla Coelho de. Juventude e políticas sociais no Brasil. Brasília: IPEA, 2009.

GUIMARÃES, Valter Soares. Formação de professores: saberes, identidade e profissão. 3. ed. Campinas: Papirus, 2004.

LAKATOS, Eva Maria; MARCONI, Marina de Andrade.

Metodologia científica: ciência e conhecimento científico, métodos científicos, teoria, hipóteses e variáveis, metodologia jurídica. São Paulo: Atlas, 2004.

LITWIN, Edith. Educação a distância: temas para o debate de uma nova agenda educativa. Porto Alegre: Artmed, 2001.

MOORE, Michael G.; KEARSLEY, Greg. Educação a distância: uma visão integrada. Traduzido por Roberto Galman. São Paulo: Thomson Learning, 2007.

MORAES, Maria Candida. Informática educativa no Brasil: uma história vivida, algumas lições aprendidas. [2010?]. Disponível em: <http://edutec.net/textos/alia/ misc/edmcand1.htm > . Acessado em: dia? abr. 2010.

OILO, Didier. De lo tradicional a lo virtual: las nuevas tecnologías de la información. Paris: UNESCO, 1998.
PIMENTA, Selma Garrido; ANASTASIOU, Léa das Graças Camargos. Docência no ensino superior. 2. ed. São Paulo: Cortez, 2005.

PRETI, Oreste. Educação a distância: fundamentos e políticas. Cuiabá: EdUFMT, 2009.

REZENDE, Flávia Amaral. Características do ambiente virtual construcionista de ensino e aprendizagem na formação de professores universitários. 2004. Dissertação (Mestrado em Multimeios). Instituto de Artes. Universidade Estadual de Campinas, Campinas, 2004. Disponível em: < http:// www.iesalc.unesco.org.ve/documentosinteres/brasil/ caracteristicas\%20del\%20aprendizaje\%20virtual \%20 -\%20Flavia\%20Amaral\%20Lazende.pdf> . Acesso em: 25 jun. 2010.

\section{SED-SC. Secretaria de Estado de Educação de} Santa Catarina. [2010?]. Disponível em: <http://www. sed.sc.gov.br>. Acesso em: 15 abr. 2010.

\section{SISUAB. Sistema com banco de dados da}

Universidade Aberta do Brasil. [2011?]. Disponível em: <http://www.uab.capes.gov.br/sisuab> . Acesso em: 7 abr. 2011.

SOUSA, Eda Coutinho B. Machado de. Panorama internacional da educação a distância. In: Em Aberto, Brasília, n. 70, p. 9-16, abr./jun. 1996.

VIANNEY João; TORRES, Patrícia; SILVA, Elizabeth. A Universidade Virtual no Brasil: os números do ensino superior a distância no país em 2002. Relatório do Seminário internacional sobre universidades virtuais na América Latina e Caribe. Quito Equador, 2003.

VIANNEY, João; BARCIA, Ricardo Miranda; LUZ, Rodolfo Joaquim Pinto da. Universidade Virtual: oportunidade de crescimento ou ameaça para as instituições de ensino superior? In: Revista Estudos. n. 26. ago. 2006.

Disponível em: <http://www.abmes.org.br/Publicacoes/ Estudos/26/vianney.htm > . Acesso em: 16 maio 2010. 